\title{
Differential Gene Expression of Antioxidant Enzymes in the Perinatal Rat Lung
}

\author{
YOUWEI CHEN AND LEE FRANK \\ Pulmonary Research Center (R-120), Departments of Medicine and Pediatrics, \\ University of Miami School of Medicine, Miami, Florida 33101
}

\begin{abstract}
It has been previously demonstrated that the developing rat lung markedly increases its catalase (CAT) and glutathione peroxidase (GP) activities during the final 10 to $15 \%$ of gestation. In the present studies, we tested whether four major antioxidant enzymes (AOE) in perinatal rat lungs might share a similar pattern of developmental $\mathrm{AOE}$ gene expression via a pretranslational mechanism. The left lungs of 18-d to term fetuses and early postnatal rat pups were used to measure the concentrations of AOE mRNA by solution hybridization and the right lungs of the same group of animals were assayed for AOE activities. Results revealed differential AOE gene expression in developing rat lungs. Whereas the CAT and GP activities progressively increased prenatally, the superoxide dismutase (SOD) activity either declined [copper-zinc $\mathrm{SOD}(\mathrm{Cu}, \mathrm{ZnSOD})]$ or remained constant [manganese SOD (MnSOD)] in late gestation. Postnatally, $\mathrm{Cu}, \mathrm{ZnSOD}$ and CAT activities progressively increased, whereas MnSOD remained constant and GP activity declined slightly. For $\mathrm{Cu}, \mathrm{ZnSOD}, \mathrm{MnSOD}$, and CAT, the activity changes were generally consistent with the patterns of changes in their mRNA concentrations in both the prenatal and postnatal period, but for GP they were not. At the time of birth, however, the mRNA levels of Cu, ZnSOD and CAT decreased $\sim 40 \%$, whereas their enzyme activities increased. For MnSOD, only a slight rise in mRNA level was observed versus $\sim 100 \%$ increase in its activity at the time of birth. These findings suggest that the $\mathrm{AOE}$ are not coordinately regulated, and that developmental regulation of AOE gene expression in the perinatal rat lung is complex and likely exerted at different levels of regulation. (Pediatr Res 34: 27-31, 1993)
\end{abstract}

Abbreviations
AOE, antioxidant enzyme
$\mathrm{Cu}, \mathrm{ZnSOD}$, copper-zinc superoxide dismutase
MnSOD, manganese superoxide dismutase
CAT, catalase
GP, glutathione peroxidase
cRNA, complementary RNA
DDC, diethyldithiocarbamate

At birth, the newborn's lung is abruptly exposed to severalfold higher oxygen tension in the ex utero environment than during its relatively hypoxic experience in utero $\left[\mathrm{PO}_{2} \cong 20-25\right.$

Received November 3, 1992; accepted February 26, 1993

Correspondence and reprint requests: Youwei Chen, M.D., Pulmonary Research Center (R-120), University of Miami School of Medicine, P. O. Box 016960, Miami, FL 33101.

Supported by University of Miami School of Medicine, Pulmonary Research Center, Departments of Medicine and Pediatrics. $\mathrm{mm} \mathrm{Hg}(2.66-3.33 \mathrm{kPa})]$ (1). To prepare the lung for this sudden transition into relative hyperoxia at the time of birth, the maturation of specific lung biochemical defensive systems may be crucial for the safe neonatal adaptation to $21 \%$ oxygen respiration.

And, in fact, it has been demonstrated now in a variety of species that development of the protective AOE system of the lung and the development of the well-investigated surfactant system share a chronologically similar late gestational pattern of maturation. The preterm fetal lung markedly increases both its surfactant content and its AOE activity levels during the final 10 to $15 \%$ of gestation (2-6). This late gestational rise in AOE activities is considered to be nature's way of preparing the lung for the safe initiation of $21 \%$ oxygen breathing.

To further explore the regulatory mechanism of normal perinatal rat lung AOE activity changes, we undertook a series of experimental studies to examine the hypothesis that four major $\mathrm{AOE}(\mathrm{Cu}, \mathrm{ZnSOD}, \mathrm{MnSOD}, \mathrm{CAT}$, and GP) might share a similar pretranslational pattern of developmental gene expression in the prenatal and early postnatal rat lung. Previous studies of single $\mathrm{AOE}$ activity/mRNA changes in the fetal or postnatal lung could not provide answers to this important developmental hypothesis or to the question of coordinate $A O E$ gene expression. The present studies were designed to use the same animal lung samples for measuring both AOE mRNA and AOE activity to determine: 1) whether changing $\mathrm{AOE}$ gene expression in the perinatal rat lung would be associated with related AOE mRNA concentration changes (i.e. suggestive of a pretranslational mechanism for the four AOE); and 2) whether regulation of each AOE's expression is the same during the late gestational period, at the time of birth, and during the early postnatal period (i.e. these four AOE are coordinately regulated).

\section{MATERIALS AND METHODS}

Animals and Breeding. We have had an ongoing rat breeding program in our laboratories for the past $10 \mathrm{y}$. Adult SpragueDawley albino female rats (Charles River Laboratories, Wilmington, MA) are bred by placing two female rats with one male in the same cage overnight, checking for sperm-positive vaginal smears the next morning, and considering the midpoint of the cohabitation period as the onset of pregnancy. The timed-pregnancy rats are maintained on standard laboratory food and water ad libitum and kept on a 12-h light/dark cycle in the accredited University of Miami Animal Care Facilities. Preterm fetuses are delivered by hysterotomy after anesthetizing the dam with pentobarbital sodium $(60 \mathrm{mg} / \mathrm{kg}$ intraperitoneally). Term-born pups are designated to be $1 \mathrm{~d}$ old at $24 \mathrm{~h}$ after birth and are raised 12 to a litter. All of the animal experimental protocols were preapproved by the University's Committee on Research Animal Welfare.

Biochemical Analyses. Lung tissue preparation. Timed preterm fetuses ( 18 to $22 \mathrm{~d}$ gestation) or newborn pups were killed by an intraperitoneal injection of pentobarbital sodium followed 
by cutting the great vessels in the abdomen. Their lungs were perfused immediately in situ with ice-cold saline via the pulmonary artery. The left atrial appendage was snipped off to facilitate drainage of the perfusate. The perfused lungs were then excised, stripped of nonpulmonary tissue, quickly frozen in liquid nitrogen and then stored at $-70^{\circ} \mathrm{C}$ for later analyses. Except for the AOE mRNA degradation studies, the left lungs of each litter of animals were used for measuring the four AOE mRNA concentrations, and the right lungs of the same litters of animals were used for measuring the four AOE activities. No differentiation between male and female rats was made.

$c R N A$ preparation. The rat cRNA for $\mathrm{Cu}, \mathrm{ZnSOD}, \mathrm{CAT}$, and GP were prepared as previously described $(7,8)$. A pGEM-Blue construct $\alpha$-actin cDNA (7) was used to synthesize $\alpha$-actin $\left[{ }^{3} \mathrm{H}\right]$ cRNA for use as an mRNA recovery marker.

A rat MnSOD cDNA clone, pSP65-RMS, was obtained from Dr. Y.-S. Ho, Laboratory of Molecular Biology, Duke University Medical Center, Durham, NC (9). The 1.4-kb EcoRI-fragment was subcloned into pGEM-7Zf (Promega Corporation, Madison, WI). After this plasmid was linearized, an ${ }^{35} \mathrm{~S}$-labeled antisense cRNA probe was synthesized using T7 RNA polymerase and $\left[{ }^{35}\right.$ S]UTP (New England Nuclear Research Products, Boston, MA). An unlabeled sense cRNA was prepared with SP6 RNA polymerase.

$A O E M R N A$ quantitation. Total nucleic acids were isolated from lung tissue as previously described (7). About $5000 \mathrm{dpm}$ ${ }^{3} \mathrm{H}$-labeled $\alpha$-actin cRNA were added at the beginning of the extraction of total nucleic acids, and the radioactivity in a portion of isolated total nucleic acids was measured to determine mRNA recovery. Quantitation of each AOE mRNA was achieved using the solution hybridization assay of Durnam and Palmiter (10). The unlabeled $\mathrm{cRNA}$ of $\mathrm{Cu}, \mathrm{ZnSOD}, \mathrm{MnSOD}, \mathrm{CAT}$, or GP were used as a standard with which we defined the range in which hybridization of each radiolabeled probe increased proportionally with added mRNA. Results of the AOE mRNA concentrations were expressed as the specific AOE mRNA molecules per mg DNA.

AOE $M R N A$ degradation. The degradation rates of $\mathrm{Cu}, \mathrm{ZnSOD}$ mRNA, CAT mRNA, and GP mRNA were measured in vitro using rat lung slices. The procedures for lung slicing and incubation in Krebs-Ringer bicarbonate medium have been described in detail $(8,11)$. Actinomycin $\mathrm{D}$ was added to the medium $(10$ $\mu \mathrm{g} / \mathrm{mL}$ ) to block RNA synthesis. At $0,3,6$, and $9 \mathrm{~h}$ of incubation in a gas phase of $95 \% \mathrm{O}_{2} / 5 \% \mathrm{CO}_{2}$, a portion of the lung tissue was quantitated for the amounts of $\mathrm{Cu}, \mathrm{ZnSOD}$ mRNA, CAT mRNA, and GP mRNA. The half-life of each mRNA was then calculated from the slope of its first-order decay curve (8).

$A O E$ activity assays. Lung tissue was homogenized in cold 2.5 $\mathrm{mM}$ potassium phosphate buffer $(\mathrm{pH} 7.8)$ in an Omnimix homogenizer (Omni International Inc., Waterbury, CT) at high speed for $60 \mathrm{~s}$. The homogenate was centrifuged at $27000 \times g$ for $45 \mathrm{~min}$ at $4^{\circ} \mathrm{C}$. The supernatant fraction was subsequently used for analyzing for AOE activities using standard spectrophotometric assays for SOD, CAT, and GP.

The method of DDC treatment was used to quantitate cytostolic $\mathrm{Cu}, \mathrm{ZnSOD}$ and mitochondrial MnSOD activities (12). One portion of each sample was incubated with $50 \mathrm{mM}$ DDC at $30^{\circ} \mathrm{C}$ for $1 \mathrm{~h}$ to inactivate $\mathrm{Cu}, \mathrm{ZnSOD}$ completely without affecting the activity of MnSOD. This portion was then dialyzed against three changes of 100 vol of $2.5 \mathrm{mM}$ potassium phosphate buffer $(\mathrm{pH}$ 7.8) with $0.1 \mathrm{mM}$ EDTA overnight. DDC-treated and untreated portions were then assayed for SOD activity by the xanthine oxidase-cytochrome $c$ method (13). Cu,ZnSOD activity was obtained by subtracting the SOD activity of the DDC-treated sample from the total SOD activity of the untreated sample. The spectrophometric assay used for CAT activity was based on following the disappearance of $\mathrm{H}_{2} \mathrm{O}_{2}$ at $240 \mathrm{nM}$ at $25^{\circ} \mathrm{C}$ (14). The GP activity assay used $0.24 \mu \mathrm{M}$ cumene hydroperoxide as substrate and monitored the rate of oxidation of NADPH at 340 $\mathrm{nm}$ (15). All enzyme activities were expressed as activity units per mg DNA. DNA in aliquots of the lung homogenates used for AOE mRNA or for AOE activity was extracted and measured using purified calf thymus DNA (Sigma Chemical Co., St. Louis, MO) as a standard (16).

Statistical Analyses. For each determination, the values for individual samples were averaged per age group, and the mean \pm SEM was calculated. Multiple age group comparisons were made by analysis of variance and Duncan's multiple range test. Kramer's extension of Duncan's test was used in cases of unequal number of replications (17). The $t$ test was used for comparing the AOE mRNA half-lives. A difference between mean values was considered significant if $p<0.05$.

\section{RESULTS}

$A O E$ activity. The developmental changes in AOE activities in perinatal rat lungs are illustrated in Figure 1. Whereas CAT and GP activities show progressive increases from fetal d 19 to 22 , MnSOD activity remains constant, and $\mathrm{Cu}, \mathrm{ZnSOD}$ shows a progressive decline in activity. In the postnatal lung between $\mathrm{d} 1$ and $5, \mathrm{Cu}, \mathrm{ZnSOD}$ activity progressively increases, as does CAT enzyme. MnSOD activity is constant between postnatal $\mathrm{d} 1$ and 5 , and GP activity declines slightly. Around the time of birth (dotted line in Figs. 1 and 2), between prenatal d 22 and postnatal d 1, the AOE activity changes are quite different from the prenatal patterns. For $\mathrm{Cu}, \mathrm{ZnSOD}$, a slight rise in activity ends the progressive prenatal decline; for MnSOD, a near 2-fold rise in activity occurs; for CAT, a $40 \%$ activity increase occurs; and for GP, a small fall in activity follows the prenatal rise up to fetal d 22 .

AOE $M R N A$ concentration. The developmental changes in AOE mRNA levels in the perinatal rat lungs are shown in Figure 2. For $\mathrm{Cu}, \mathrm{ZnSOD}$ mRNA (except fetal d 18 to 19), MnSOD mRNA, and CAT mRNA, the prenatal pattern of changes between gestational d 18 and 22 are similar to the pattern of activity changes for these AOE (Fig. 1). For GP, however, the pattern of decreasing prenatal mRNA levels is opposite to the increasing GP activities observed. Postnatally, between $\mathrm{d} 1$ and 5, the mRNA patterns essentially reflect the activity changes for these four AOE. Around the time of birth, between prenatal d 22 and postnatal $\mathrm{d} 1$, for $\mathrm{Cu}, \mathrm{ZnSOD}$ and CAT the mRNA changes are exactly opposite to the activity changes. For MnSOD, only a small positive mRNA change is observed versus a near $100 \%$ increase in MnSOD activity. GP activity and mRNA patterns are now similar.

$A O E$ mRNA stability. The tested AOE mRNA half-lives for $\mathrm{d}$ 18 and $\mathrm{d} 21$ of gestation are summarized in Table 1 . None of the AOE mRNA half-lives were significantly different from one another at gestational d 18 or 21 .

\section{DISCUSSION}

"The truth is rarely pure, and never simple."-Oscar Wilde, The Importance of Being Earnest

Aerobic cell survival requires that the cell has adequate constitutive antioxidant defense mechanisms, and survival in hyperoxia requires that cells have the capacity to rapidly respond to oxidant stress by an increase in the activity of those defense systems that can detoxify increased reactive species of oxygen and thereby prevent oxygen toxicity $(18,19)$. The AOE are the key protective system in aerobic cells that protect against reactive oxygen free radicals and their damaging interaction with vital cell components-proteins (enzymes), unsaturated lipids, and DNA.

As indicated in the introduction, the previously reported late gestational elevation in AOE activities has been proposed as a critical means of protecting the newborn's lung from the relative hyperoxia it encounters at the moment of birth (2-5). Because the AOE had been shown in five different species (including the rat) to share a similar late gestational rise in activity in fetal 


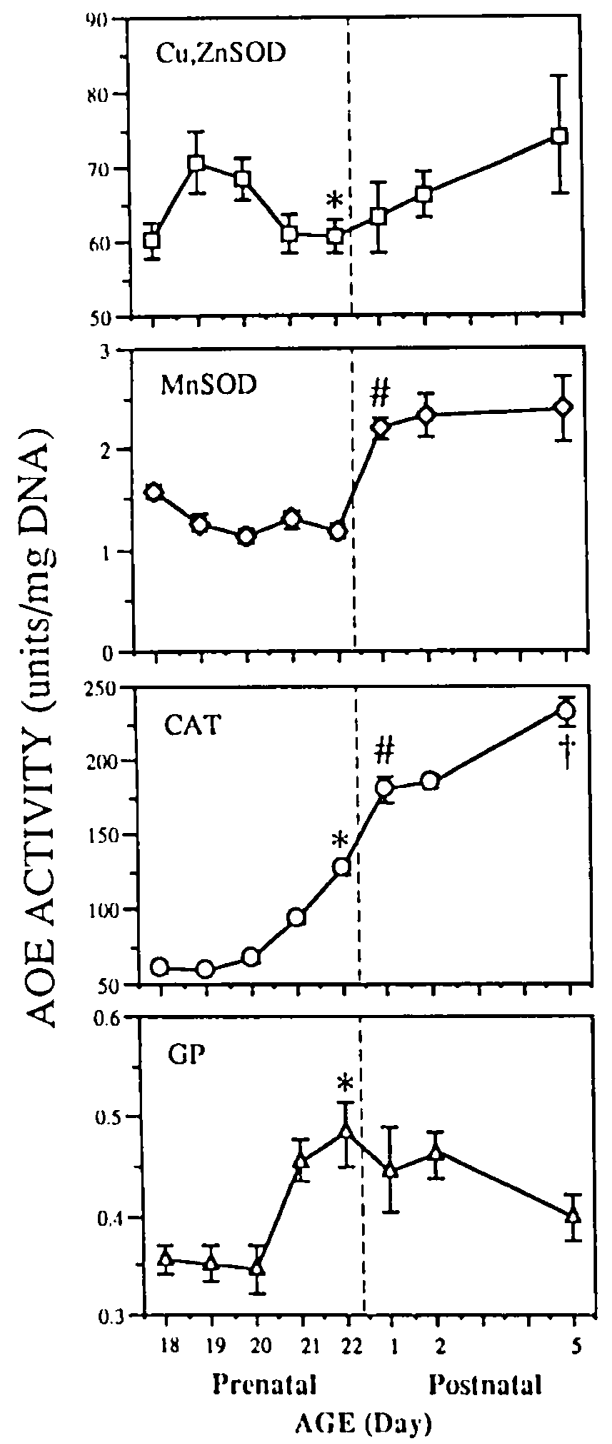

Fig. 1. Developmental changes in rat lung AOE activities. Rat right lungs were obtained at the indicated prenatal and postnatal ages and assayed for $\mathrm{Cu}, \mathrm{ZnSOD}, \mathrm{MnSOD}, \mathrm{CAT}$, and GP activities. Dotted line indicates birth. Values are based on five to seven litters for each fetal age for the prenatal period, and four to five litters for each postnatal age. Mean \pm SEM are shown. ${ }^{*}, p<0.05$ for prenatal d 22 vs prenatal d 19. $\#, p<0.01$ for postnatal d 1 vs prenatal d 22. $\dagger, p<0.01$ for postnatal d 5 vs postnatal d 1 .

lungs, we wondered whether these $\mathrm{AOE}$ in the prenatal fetal lung (and perhaps also extending to the postnatal lung) might share a similar pattern of developmental $\mathrm{AOE}$ gene regulation. This hypothesis was also based on two previously published studies on the mechanisms responsible for the late gestational change of rat lung $\mathrm{Cu}, \mathrm{ZnSOD}$ and $\mathrm{CAT}$ activities, respectively. Hass et al. (7) earlier found that in late gestation the synthesis of rat lung $\mathrm{Cu}, \mathrm{ZnSOD}$ was regulated pretranslationally. More recently, Clerch et al. (20) reported that fetal rat lung CAT mRNA was elevated in late gestation and that the half-life of CAT mRNA was constant during late gestation, leading to the conclusion that CAT expression was regulated, at least in part, at the level of gene transcription. The molecular biology studies described herein were thus undertaken to extend these previous singleenzyme studies and to determine whether a common mechanism might be controlling the normal gene expression of four major $\mathrm{AOE}$ in the late prenatal and early postnatal rat lung. The chosen experimental design of using the same animal lung samples for measuring AOE mRNA concentrations as well as AOE activities

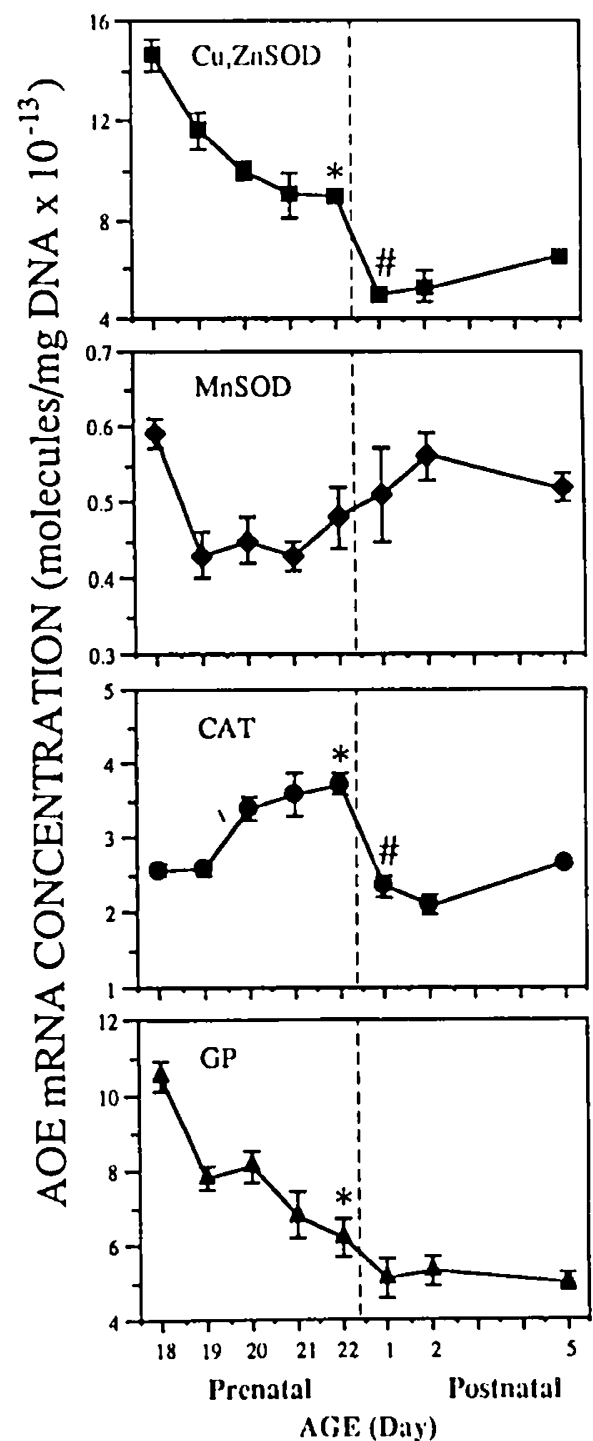

Fig. 2. Developmental changes in concentration of rat lung AOE mRNA. Rat left lungs from same samples as Figure 1 were assayed for $\mathrm{Cu}, \mathrm{ZnSOD}$ mRNA, MnSOD mRNA, CAT mRNA, and GP mRNA by solution hybridization using respective ${ }^{35} \mathrm{~S}$-labeled cRNA probes. Dotted line indicates birth. Mean \pm SEM are shown. ${ }^{*}, p<0.05$ for prenatal $\mathrm{d}$ 22 vs prenatal d 19. \#, $p<0.01$ for postnatal d 1 vs prenatal d 22.

Table 1. Lung AOE $m R N A$ stability

\begin{tabular}{lccc}
\hline & \multicolumn{3}{c}{ mRNA half-lives $(\mathrm{h})$} \\
\cline { 2 - 4 } & Cu,ZnSOD & CAT & GP \\
\hline Gestation d 18 (12/6) & $8.3 \pm 0.7$ & $7.0 \pm 0.5$ & $8.8 \pm 1.0$ \\
Gestation d 21 (5/5) & $9.5 \pm 1.2$ & $9.3 \pm 1.4$ & $8.3 \pm 1.0$ \\
$p$ & NS & NS & NS \\
\hline
\end{tabular}

* Values are mean \pm SEM for gestational age ( $n$ litters $/ n$ experiments), using rat lung slices. NS, $p>0.05$ for $\mathrm{d} 21$ vs $\mathrm{d} 18$ values.

could provide, we believe, more valid activity versus mRNA concentration data for comparative purposes than previous approaches using different animal/litter lungs for the separate measurements.

Our findings (Figs. 1 and 2) indicate that the developmental pattern of AOE gene expression is more complex than single AOE analyses have suggested. Analysis of Figures 1 and 2 led us to group the comparative perinatal changes in AOE activity and mRNA concentration into three separate time components, i.e. prenatal (gestational d 19 to 22), birth (between prenatal d 22 
and postnatal d 1), and postnatal (postnatal d 1 to 5). It appears to us that the regulation of $\mathrm{AOE}$ gene expression is changing across these three time periods. Prenatally, for $\mathrm{Cu}, \mathrm{ZnSOD}$ (except fetal d 18 to 19), MnSOD, and CAT, the activity changes noted were consistent with the pattern of change in mRNA concentration, suggesting a pretranslational mode of AOE gene expression [as previously concluded for $\mathrm{Cu}, \mathrm{ZnSOD}$ synthesis (fetal d 21,22 ) by Hass et al. (7) and Clerch et al. for CAT (20)]. The lack of any difference in mRNA half-lives at d 18 of gestation and $\mathrm{d} 21$ of gestation for any of the AOE measured (Table 1) would seem to rule out a mechanism of stabilization or destabilization of mRNA transcripts in late gestation. In contrast to the other AOE, for GP enzyme it is obvious that pretranslational regulation of GP activity cannot be involved, because activity levels substantially increase despite progressively decreasing GP mRNA levels in late gestation. Thus, GP gene expression must be regulated at a translational or posttranslational level prenatally.

In comparing our prenatal $\mathrm{AOE}$ activity patterns with those reported in the literature, some problems arise. Earlier studies from our own laboratory indicated a progressive prenatal rise in total SOD activity (2), which conflicts with our present prenatal $\mathrm{Cu}, \mathrm{ZnSOD}$ data. This is possibly due to the different enzyme assay used in these two studies (DDC treatment versus no DDC treatment). However, we cannot explain why the absolute levels of SOD, CAT, and GP are all quite different from those found in this previous study, nor why the relative changes in late gestational CAT and GP activity are considerably lower in the present versus the previous study. In comparing our prenatal AOE activity patterns with other literature reports, we noted that Tanswell and Freeman (21) found prenatal increases in rat lung CAT, GP, and Cu,ZnSOD activities between $\mathrm{d} 18$ and term, but MnSOD activity decreased in late gestation. However, subsequent studies of developmental changes in rat lung AOE activities reported different findings $(22,23)$. Of interest is that similarly increasing late gestational patterns of CAT and GP activities were consistently found (as in the present studies), but these consistent $A O E$ findings were associated with variable fetal lung SOD developmental patterns reported by different laboratories. For example, Gerdin et al. (22) found that total SOD activity showed a slight increase only between gestational d 19 and 20 , and no significant changes were seen during the last days of intrauterine life. Hass $e t$ al. (23) found both $\mathrm{Cu}, \mathrm{ZnSOD}$ activity and specific $\mathrm{Cu}, \mathrm{ZnSOD}$ protein content decreased from gestational d 20 to 21 . Thus, whereas our developmental patterns for CAT, GP, and MnSOD activities in the prenatal rat lung (Fig. 1) are similar to those reported by Tanswell and Freeman as well as these other investigators, the prenatal pattern of $\mathrm{Cu}, \mathrm{ZnSOD}$ activity that we measured coincides more closely with the reports by Gerdin et al. and Hass et al.

Postnatally, it may superficially appear that a pretranslational mode of regulation may be operative for the four tested AOE, because the pattern of change in enzyme activities is essentially parallel to the pattern of change in enzyme mRNA levels (Figs. 1 and 2). However, postnatally (as compared with prenatally), the amount of $\mathrm{AOE}$ activity change that is found in comparison with the amount of change in mRNA level dramatically changes so that relatively large changes in AOE activity occur in the face of relatively small changes in mRNA levels. This implies to us that additional means of regulation of $\mathrm{AOE}$ gene expression are now operative, e.g. increased translational efficiency and increased AOE stability. In their study on developmental regulation of rat lung $\mathrm{Cu}, \mathrm{ZnSOD}$, Hass et al. (23) found that the half-life of this enzyme increased from $\sim 6 \mathrm{~h}$ during the age interval of prenatal d 21 to postnatal $\mathrm{d} 1$, to $\sim 11 \mathrm{~h}$ at postnatal age 1 to 3 $\mathrm{d}$ and then progressively increased to adulthood. This result and our current experimental data would suggest that this posttranslational mechanism is involved, at least in part, in the overall regulation at least for $\mathrm{Cu}, \mathrm{ZnSOD}$ in the postnatal rat lung.

At the time of birth, between our d 22 prenatal and d 1 postnatal time points, it appears as if the normal means of pretranslational regulation of $\mathrm{AOE}$ gene expression for $\mathrm{Cu}, \mathrm{ZnSOD}, \mathrm{MnSOD}$, and CAT up to this time is suddenly altered, perhaps because of the sudden change in oxygen tension experienced by the lung cells with $21 \%$ oxygen breathing. This abrupt physiologic change appears to be accompanied by a (necessary) resetting of $\mathrm{AOE}$ gene regulation in the lung cells. This is reflected perhaps in the relatively large fall in mRNA levels for $\mathrm{Cu}, \mathrm{ZnSOD}, \mathrm{CAT}$, and GP; and the rise in MnSOD mRNA concentration (and the much larger rise in MnSOD activity, perhaps secondary to the increased mitochondrial versus glycolytic respiration after birth). After this abrupt transitory period, AOE gene expression may again continue to be pretranslationally regulated, but, again, other translational or posttranslational means of regulation now appear to become importantly activated. One can speculate that it is as though after birth the comparatively lower AOE mRNA levels reflect a partial "turning off' of the AOE genes, with the genes being kept in a lowered expression rate.

The finding that these four AOE are not coordinately regulated, and that different levels of regulation may mediate gene expression for the different lung AOE during the perinatal period, is actually not as unique as it may first appear. For example, Snyder and Wohlford-Lenane $(24,25)$ found that for the three surfactant-associated proteins (SP-A, SP-B, and SP-C), their mRNA exhibited significantly different temporal and cellular patterns of induction during fetal rabbit lung development. The independent regulation of SP-A, SP-B, and SP-C in the fetal lung has also been demonstrated in the developing human lung and in the rat lung (26). Also, during hyperoxic exposure, there is evidence that surfactant lipids and the different surfactant protein responses to high oxygen exposure are also individually regulated (27). In terms of AOE, differential regulation of specific AOE in response to oxidants (28) or to hyperoxia (29) was reported recently in cultured human endothelial cells and in hamster tracheal epithelial cells in vitro. In the well-studied multiple gene response elements to oxidant stress in prokaryotes, different AOE are under the control of either the oxyR regulon (for CAT, glutathione reductase) or the sox $\mathrm{R}$ regulon (for $\mathrm{MnSOD}$, glucose6-phosphate dehydrogenase) (30). Thus, gene expression of AOE does not appear to be coordinately regulated in specific lung cell types in vitro, in bacteria, or developmentally in the perinatal animal lung.

Addendum. After the submission of our manuscript, we became aware of a just-published study by Clerch and Massaro (31). These authors report finding no increases in pulmonary MnSOD activity and mRNA during late gestation in the rat, similar to our findings in this manuscript. For the other $A O E$ examined, they found increased prenatal lung GP activity, again similar to our present findings. However, they found essentially no change in GP mRNA concentration in late gestation, which conflicts with our GP data (decline in GP mRNA). Historical data only are provided for the other $\mathrm{AOE}(\mathrm{Cu}, \mathrm{ZnSOD}$ and CAT). Also, no attempt to measure both AOE enzyme activity and AOE mRNA in the same animal lungs is indicated.

Acknowledgments. The authors thank Dr. Ye-Shih Ho for generously providing the rat MnSOD cDNA clone, Dr. Philip Whitney for helpful discussion throughout these studies, and Martha Sanchez for her assistance with the manuscript preparation.

\section{REFERENCES}

1. Dejour P 1981 Principles of Comparative Respiratory Physiology. Elsevier/ North Holland, Amsterdam, pp 147-171

2. Frank L, Sosenko IRS 1987 Prenatal development of lung antioxidant enzymes in four species. J Pediatr 110:106-110

3. Frank L, Sosenko IRS 1987 Development of lung antioxidant enzyme system in late gestation: possible implications for the prematurely born infant. J Pediatr 110:9-14 
4. Sosenko IRS, Frank L 1987 Guinea pig lung development: antioxidant enzymes and premature survival in high $\mathrm{O}_{2}$. Am J Physiol 252:R693-R698

5. Frank L, Groseclose EE 1984 Preparation for birth into an $\mathrm{O}_{2}$-rich environment: the antioxidant enzymes in the developing rabbit lung. Pediatr Res 18:240-244

6. Walther FJ, Wade AB, Warburton D, Forman HJ 1991 Ontogeny of antioxidant enzymes in the fetal lamb lung. Exp Lung Res 17:39-45

7. Hass MA, Iqbal J, Clerch LB, Frank L, Massaro D 1989 Rat lung Cu, Zn superoxide dismutase. Isolation and sequence of a full-length $\mathrm{cDNA}$ and studies of enzyme induction. J Clin Invest 83:1241-1246

8. Chen Y, Whitney P, Frank L 1993 Negative regulation of antioxidant enzyme gene expression in the developing fetal rat lung by prenatal hormonal treatments. Pediatr Res 33:171-176

9. Ho Y-S, Crapo JD 1987 Nucleotide sequences of cDNAs coding for rat manganese-containing superoxide dismutase. Nucleic Acids Res 15:10070

10. Durnam DM, Palmiter RD 1983 A practical approach for quantitating specific mRNAs by solution hybridization. Anal Biochem 131:385-393

11. Clerch LB, Whitney PL, Massaro D 1987 Rat lung lectin synthesis, degradation and activation. Biochem J 245:683-690

12. Iqbal J, Whitney P 1991 Use of cyanide and diethyldithiocarbamate in the assay of superoxide dismutases. Free Rad Biol Med 10:69-77

13. McCord JM, Fridovich I 1969 Superoxide dismutase: an enzymic function for erythrocuprein (hemocuprein). J Biol Chem 244:6049-6055

14. Holmes RS, Masters CJ 1970 Epigenetic interconversions of the multiple forms of mouse liver catalase. FEBS Lett 11:45-48

15. Paglia DE, Valentine WN 1967 Studies on the quantitative and qualitative characterization of erythrocyte glutathione peroxidase. J Lab Clin Med 70:158-169

16. Schneider WC 1957 Determination of nucleic acids in tissues by pentose analysis. Methods Enzymol 3:680-684

17. Steel RGP, Torrie JH 1960 Principles and Procedures of Statistics. McGrawHill, New York

18. White CW 1988 Pulmonary oxygen toxicity: cellular mechanisms of oxidant injury and antioxidant defense. In: Bancalari E, Stocker JT (eds) Bronchopulmonary Dysplasia. Hemisphere, Cambridge, MA, pp 22-41

19. Freeman BA, Topolsky MK, Crapo JD 1982 Hyperoxia increases oxygen radical production in rat lung homogenates. Arch Biochem Biophys 216:477-484

20. Clerch LB, Iqbal J, Massaro D 1991 Perinatal rat lung catalase gene expression: influence of corticosteroid and hyperoxia. Am J Physiol 260:L428-L433

21. Tanswell AK, Freeman BA 1984 Pulmonary antioxidant enzyme maturation in the fetal and neonatal rat. I. Developmental profiles. Pediatr Res 18:584587

22. Gerdin E, Tyden O, Eriksson UJ 1985 The development of antioxidant enzymatic defense in the perinatal rat lung: activities of superoxide dismutase, glutathione peroxidase, and catalase. Pediatr Res 19:687-691

23. Hass MA, Massaro D 1987 Developmental regulation of rat lung $\mathrm{Cu}, \mathrm{Zn}$ superoxide dismutase. Biochem J 246:697-703

24. Snyder JM, Wohlford-Lenane CL 1992 In situ hybridization of surfactantassociated protein mRNAs in developing rabbit lung tissue. Am Rev Respir Dis 145:A28(abstr)

25. Wohlford-Lenane CL, Snyder JM 1992 Localization of surfactant-associated proteins SP-A and SP-B mRNA in rabbit fetal lung tissue by in situ hybridization. Am J Respir Cell Mol Biol 7:335-343

26. Ballard PL 1989 Hormonal regulation of pulmonary surfactant. Endocr Rev 10:165-181

27. Minoo P, King RJ, Coalson JJ 1992 Surfactant proteins and lipids are regulated independently during hyperoxia. Am J Physiol 263:L291-L298

28. Shull S, Heintz NH, Periasamy M, Manohar M, Janssen YMW, Marsh JP, Mossman BT 1991 Differential regulation of antioxidant enzymes in response to oxidants. J Biol Chem 266:24398-24403

29. Jornot L, Junod AF 1992 Response of human endothelial cell antioxidant enzymes to hyperoxia. Am J Respir Cell Mol Biol 6:107-115

30. Demple B 1991 Regulation of bacterial oxidative stress genes. Ann Rev Genet 25:315-317

31. Clerch LB, Massaro D 1992 Rat lung antioxidant enzymes: differences in perinatal gene expression and regulation. Am J Physiol 263:L466-L470 